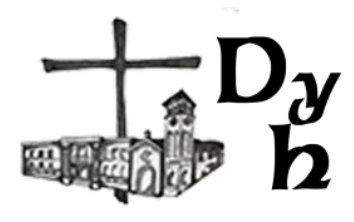

La originalidad tomista frente a la denuncia heideggeriana Julián Lanusse

Dios y el hombre, vol. 5, n. 2, e083, 2021

ISSN 2618-2858 - https://doi.org/10.24215/26182858e083 https://revistas.unlp.edu.ar/DyH/index Cátedra libre de pensamiento cristiano - UNLP Seminario Mayor San José La Plata, Buenos Aires, Argentina

\title{
LA ORIGINALIDAD TOMISTA FRENTE A LA DENUNCIA HEIDEGGERIANA
}

The Thomist Originality vs. the Heideggerian Complaint

\author{
Julián Lanusse \\ julilanusse19@gmail.com \\ Universidad Nacional de La Plata - La Plata - Argentina
}

\section{Resumen}

En la presente monografía, enmarcada como proyecto final de la materia Metafísica de la Licenciatura en Filosofía a distancia de la Universidad Católica de La Plata, se esboza sintéticamente el aspecto novedoso que aporta la ontología tomista respecto a la primacía del acto de ser, para luego relacionarla con la denuncia que, en la contemporaneidad filosófica, realiza Martín Heidegger bajo el nombre de Olvido del Ser.

Palabras Claves: Acto de Ser - Esencia - Martín Heidegger - Metafísica - Tomás de Aquino

\section{Abstract}

The present study, framed as final project for the subject "Metafísica de la Licenciatura en Filosofía" at Universidad Catolica de La Plata, briefly exposes the innovative approach that Thomistic Ontology offers regards the primacy of the act of being. Furthermore, this viewpoint will be contrasted with Martin Heidegger's allegation found in Contemporary Philosophy under the name of "forgetfulness of being".

Keywords: act of being - essence - Martin Heidegger - metaphysics - Thomas Aquinas 


\section{Introducción}

En un artículo publicado recientemente (Lanusse, 2020), mencioné taxativamente la importancia significativa que tiene la filosofía esbozada en el seno de la Antigua Grecia. En dicha oportunidad, comenté la famosa frase del filósofo Whitehead $(1929,63)$ referida a que todas las producciones filosóficas occidentales son meramente una respuesta, o por lo menos un intento, a aquella filosofía de antaño. Evidentemente, coincidamos parcial o totalmente con el filósofo inglés, es indudable que debemos prestar atención a los aportes de los antiguos griegos ya que es justamente allí donde observamos el pasaje del mito al Logos ${ }^{1}$. Esto, a pesar de tener una connotación abstracta, se plasma claramente en ejemplos históricos. Pensemos, por ejemplo, en la historia épica de Heródoto en contraposición a la historia científica de Tucídides, utilizando la duda como método. O también en los relatos míticos de Homero y Hesíodo frente a los esbozos de los filósofos presocráticos inaugurando la filosofía de la naturaleza que realizaba admirables esfuerzos en busca del arché. Con esto queremos mostrar, y estoy convencido de ello, de que la Antigua Grecia merece una especial atención, a pesar de ser olvidada muchas veces por la academia.

Sin dudas, Aristóteles se ubica como uno de aquellos grandes pensadores que recorrieron las calles de Atenas interrogándose acerca de las inquietudes más profundas y complejas de nuestra existencia. Si bien no pretendemos aquí centrarnos en los planteos aristotélicos, considero importante realizar una breve mención del Estagirita debido la notable influencia que tiene su Metafísica en occidente. Evidentemente, y creo que esta es una afirmación que encontrará consenso fácilmente, no podemos entender a Tomas de Aquino sin primero detenernos en los escritos aristotélicos. A la hora de acercarnos a los planteos que el preceptor de Alejandro realiza en su obra, aparece la necesidad de definir a las ciencias particulares como aquellas que estudian una zona particular del ente, es decir, que se encargan de analizar un atributo especifico, un ente en cuanto es un determinado tipo de ente. En contraposición a esto, Aristóteles propone su filosofía primera que versa sobre el ente en cuanto ente. Así el Estagirita habla de una ciencia que estudie "el ente

\footnotetext{
1 Con esta afirmación no le quitamos relevancia a los mitos debido a que tienen una importancia espiritual y funcional sumamente importante para aquellas civilizaciones y culturas. Sin embargo, es necesario plantear el claro pasaje ocurrido en la Antigua Grecia.
} 


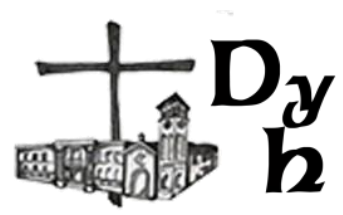

en cuanto ente y lo que le que corresponde de suyo" (Aristóteles, 2018,41), la cual no sería particular como aquellas ciencias que para su estudio recogen solamente un atributo, sino que se nos aparece como universal y necesaria. Luego plantea que, a pesar de decirse de muchas maneras, el ser es único por naturaleza, es decir, es un concepto análogo pues, a pesar de las diferencias, todos comparten que son seres. Debido a esto, el filósofo sigue su argumento diciendo que le corresponde a una sola ciencia estudiar al ser en cuanto ser, por lo que sí toda ciencia se define como el estudio de principios o causas, la Filosofía primera debería estudiar la causa del ser, esta es, la substancia. Con el paso del tiempo, esta Filosofía primera será conceptualizada como Metafísica, ciencia que se encarga de establecer los cimientos para todas las demás ciencias. En este punto, es necesario recordar como Aristóteles define a los atributos como géneros o modos de ser, los cuales abarcan la substancia y nueve tipos de accidentes, de forma tal que permiten distinguir al estudio de la substancia encargado a la Metafísica, y el estudio de las ciencias particulares analizando, cada una de ellas, un atributo específico.

La novedad aristotélica la encontramos en su definición de sustancia (ousía) como aquello que existe por sí mismo, es decir, lo que permanece igual a pesar de las mutaciones sin necesidad de otra cosa para existir, en contraposición a los accidentes que son inherentes a las substancias. Con esto, Aristóteles afirma que ser se puede decir de varios sentidos, lo que lo lleva a diferenciar la substancia, que es aquello que es siempre sujeto y nunca predicado, y el ser en otro que recibe el nombre de accidente. Además, distingue entre la materia que es aquello de lo que está hecha una cosa, y la forma que es aquello que una cosa es. Por otro lado, afirma que todo ser es en acto, ya que es real, pero también es en potencia ante la posibilidad de ser distinto, por lo que el movimiento se define como el paso de la potencia al acto. Considerando esto, Aristóteles define al hombre como una substancia compuesta de materia (cuerpo) y forma (alma) y, como en toda substancia no existe la materia sin forma ni la forma sin materia, cuando este muere el alma deja de existir.

Sin embargo, el problema de la metafísica aristotélica es que no considera una distinción real entre ser y esencia, es decir, entre "ser" y "ser esto". En otras palabras, Aristóteles no concibe una diferencia entre hacer que el 
ente sea y hacerlo ser lo que es. De esta forma "la esencia y el ser de una entidad constituyen la misma cosa o, dicho de otro modo, la ousía es un bloque monolítico donde "ser tal" y "ser" son ambos una misma cosa" (Marenghi, 2018, 36). En síntesis decimos que la ontología de la esencia o esencialismo de Aristóteles afirma que lo realmente real es la esencia.

A pesar de esto, Aristóteles sienta las bases, especialmente con su doctrina del acto y la potencia, para la distinción real entre ser y esencia que vislumbrará detalladamente Tomas de Aquino y que analizaremos a continuación.

\section{La Originalidad Tomista}

Lo primero que debemos mencionar en este apartado es que la filosofía tomista, a pesar de retomar y basarse en la ontología esencialista de Aristóteles, la supera notablemente al distinguir entre esencia y ser, entendiendo a este último como acto de la primera. Aquí encontramos la verdadera novedad del pensamiento del Aquinate.

Antes de ahondar en el pensamiento de Tomas, debemos aclarar que, si bien la diferencia real entre ser y esencia fue elaborada originalmente por este autor, el primero en mencionarla es Boecio al acuñar la fórmula: quod est y quo est. A su vez, es célebre su afirmación que señala: Diversum est esse et quod est ${ }^{2}$.

Ahora bien, el planteo tomista se argumenta principalmente en que el ser no pertenece a la noción de esencia. Se trata de una distinción entre un principio constitutivo del ente que es anterior a la esencia, designado con el infinitivo del verbo ser, a saber, el esse. Analíticamente podemos observar que, a diferencia del preceptor de Alejandro, Tomás establece una diferencia entre "lo que" el ente es y que el ente "es". Siguiendo la comparación con Aristóteles podemos vislumbrar claramente que mientras que para él lo realmente real es la substancia, para Tomás lo real se encuentra en el esse. En palabras de Gilson $(1951,108)$ "el corazón de lo real no es simplemente la sustancia que es, ni siquiera la forma cuyo acto le hace ser lo que es, sino el esse cuyo acto le hace existir".

\footnotetext{
${ }^{2}$ Cf. De hebdomadibus, L. 64, 1311
} 


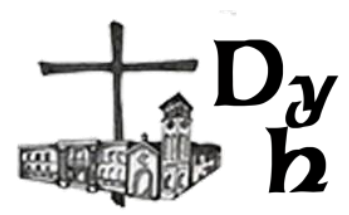

Sin intención de sondear nuevamente en lo mismo, es necesario remarcar la importancia de la cuestión. Tomás no realiza simplemente una distinción de razón, sino que ahonda hacia una nueva dimensión existencial planteando una distinción en el seno del ente real $y$, por tanto, designando al esse como el fundamento ultimo de todo lo que existe. Por eso afirma categóricamente que "el ser es lo más perfecto en todas las cosas, es la actualidad de todos los actos y la perfección de todas las perfecciones" (2001, q.7, a.2, ad 9.).

Luego de la muerte del Doctor Angélico, sus alumnos, entre ellos Egidio Romano, desviaron el pensamiento original tomista en un intento de seguir con su teorización. De esta manera, confundiendo los planteos de Tomás, plantearon que la esencia y el ser son dos cosas realmente diferentes, concluyendo que "ya no son algo del ente sino entes" (Marenghi, 2019, 115). Ser y esencia, originalmente considerados como coprincipios entitativos en la obra del Aquinate, se sustancializan de forma tal que, entre ellos, se produce una distinción "inter-res" en vez de una "intra-rem". Considerando esto, es necesario pasar a aclarar la cuestión.

Un ejemplo de esto lo encontramos en las propias palabras de Egidio Romano cuando afirma que "La esencia y el ser son dos cosas realmente diferentes $^{\prime \prime}$. Como observamos anteriormente, el alumno de Tomas sigue de cerca la línea aristotélica para plantear que la forma hace que la cosa sea un ente. Con esto queremos decir que, enmarcándose como un pensamiento en sintonía con el esencialismo, el alumno de Tomás afirma que antes de tener actualidad, la esencia goza de cierta realidad. En definitiva, estamos frente a un pensador que sostiene que la esencia es sin el esse. El verdadero problema tanto aquí como en Aristóteles, y en otros filósofos como Avicena, Enrique de Gante, Duns Scoto y Suárez (Marenghi, 2019), es que, ignorando que la esencia sin el esse no es nada, la conciben como preexistente a la actualidad que le otorga éste. Lejos de eso, el Aquinante no duda en plantear que es el esse el acto primero por el cual la cosa existe. Otra vez, sin el acto de ser la esencia no es nada. En síntesis, decimos que "no hay que pensar en que la essentia pueda

\footnotetext{
${ }^{3}$ Cf. Egidio Romano, Theoremata, Th. XIX.
} 
existir sin el esse, como si fuese algo anterior a lo que adviniese el esse, porque el esse es el acto fundante de la realidad total de la essentia" (Marenghi, 2018, 42).

La novedad tomista que le permite superar el esencialismo aristotélico es justamente la que le abre la puerta rumbo al planteo de la doctrina de la participación debido a que Tomás afirma que ningún ente tiene el ser por sí mismo, sino por otro, por lo cual el ente recibe al ser. Con esto sostiene que, a pesar de decir que el acto de ser funda al ente y, en consecuencia, a la esencia, el Doctor Angélico se apoya en la doctrina de la participación para esbozar la analogía del ente planteando que el esse se dice de todas las realidades, pero analógicamente. Con esto, el Aquinante afirma que los participantes son aquellos de lo que participan de un modo igual y de otro diverso. En otras palabras, podemos decir que Dios "es" el ser mientras que los entes "tienen" ser, de forma tal que las cosas tienen ser por participación, siendo la causa de todo ente el Ser Absoluto. Lejos de la acepción física del término, Tomás entiende el concepto de participación en un sentido metafísico refiriéndose a poseer parcialmente lo que otro tiene totalmente. Considerando esto, es interesante retomar los aportes de Fabro (2009) respecto a que las fuentes principales que recoge Tomas son la inspiración horizontal aristotélica y la inspiración vertical platónica, especialmente con sus nociones de participación y esse intensivo.

Además de esto, el Aquinante sistematiza una jerarquía ontológica que establece distintos grados en base a la forma de recibir al ser. De allí que, como comentábamos anteriormente, el esse se dice analógicamente de todas las realidades. Aquello que señala la manera en la cual el ente participa del Ser absoluto es la esencia. De allí que, a pesar de que los distintos grados ontológicos como el angelical, el humano, el animal, el vegetal y el mineral son en virtud del acto de ser participado, lo reciben de manera distinta en base a su esencia propia. En términos coloquiales podríamos visualizar a la esencia como el recipiente que recibe al esse de una determinada forma, recordando la supremacía ontológica de este último. Considerando estos esbozos es que podemos entender aquella afirmación tomista que versa "conviene decir que Dios está en todas las cosas de manera íntima" (Tomás de Aquino, 2006, I, q. 8, a. 1.) 


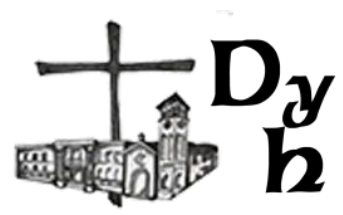

En conclusión, Tomás afirma que el esse es un acto de una determinada potencia, la esencia, que lo limita. Por lo tanto, distinguimos tres elementos en cualquier sujeto creado: la Esencia o naturaleza que es real, pero en cada sujeto, es decir, no existe sola; los accidentes que son añadidos que no son parte de la naturaleza de la especie; y el acto de ser que es lo constitutivo real del sujeto. Ser sujeto es tener el acto de ser substancial que, junto con la esencia, constituyen el ente singular. Con esto, el Aquinante plantea que constituirse en persona pertenece al orden trascendental pues implica la participación del ser. De allí, podemos entender la afirmación tomista respecto a que el obrar sigue al ser porque, antes que nada y de modo fundante, el ente es.

En la comprensión que Tomás hace del esse como el verdadero actus essendi, lo cual lo ubica como la instancia fundante de la realidad de la esencia y de la verdad de los juicios del entendimiento, encontramos la verdadera originalidad tomista. En ella encontramos el verdadero pasaje de la ontología de la esencia, creada por Aristóteles y continuada por vastos filósofos a lo largo de la historia, y la ontología del ser que afirma la supremacía del esse como aquel acto primero sin el cual la esencia no es. En sintesis, decimos que la novedad que plantea Tomás de es que el ente es un compuesto de ser y esencia, siendo el primero, acto y el segundo, potencia, el primero, determinante y el segundo, determinado, el primero, fundante y el segundo, fundado.

Además de reconocer la importancia del pensamiento tomista, es necesario remarcar, quizás para asombro de muchos pensadores críticos del tomismo, que fue Tomás quien, siete siglos antes, planteo la diferencia ontológica y, sin nombrarlo aún de esa manera, denuncio el olvido de ser que, en la contemporaneidad filosófica, planteo el mismo Martín Heidegger y que expondremos en el próximo apartado.

\section{El Olvido del Ser}

Por lo dicho anteriormente pareciera que, a lo largo de la historia, la inquietud filosófica por excelencia ha sido la referida al ser. Incluso, si nos remontamos hasta el mismo Aristóteles, encontramos su afirmación respecto a que "el problema antes y ahora, siempre discutido y nunca resuelto: ¿qué es el ser?" (Aristóteles, 2018, Z 1028 2-4). De hecho, podríamos decir que, aún en la vida cotidiana tenemos un trato domestico con el ser ya que de cada cosa que 
hacemos o decimos podemos decir que "es". Hay, si se me acepta el término, cierta tiranía del ser porque nada puede quedar fuera de él. Sin embargo, en el año 1927 Martin Heidegger escribe una obra titulada Ser y Tiempo en la cual denuncia categóricamente que la pregunta filosofía por antonomasia nunca ha sido planteada como tal, por lo cual "toca ahora empezar por despertar de nuevo una comprensión del sentido de esta pregunta" (Heidegger, 1997, 1). Sintéticamente, podemos decir que el filósofo alemán parte de la premisa que, a pesar de que la cotidianeidad nos proporciona evidencia de que las cosas son, para que sepamos que todo esto es, debemos preguntarnos qué significa ser.

Seguramente el lector ya puede pesquisar hacia donde me dirijo argumentalmente. Heidegger, en esta denuncia, sostiene que la filosofía a lo largo de los años no se ha ocupado verdaderamente del ser y, en consecuencia, se propone teorizar acerca de esto. Sin embargo, y esto es necesario aclarar, la pregunta heideggeriana motivada por su denuncia no se trata simplemente de una mera reiteración de lo que la metafísica ya se ha preguntado, sino que refiere a aquel fundamento que, no solo no se ha pensado, sino que fue condenado al olvido. En otras palabras, podemos decir que el filósofo alemán se propone un paso atrás en busca de lo que ha permanecido oculto para la metafísica. Esto recuerda a lo que afirma Lewis (1943) respecto a que, en determinadas ocasiones, crecer significa tomar consciencia del error, dar un paso hacia atrás y volver al camino correcto.

Ahora bien, Heidegger nos habla de un verdadero olvido del ser (Seinsvergessenheit) ya que, a pesar que el ser de los entes no "es" el mismo un ente, la metafísica ha caído en una confusión dejando de lado el ser para ocuparse del ente. Si bien hablar de ente lleva una implícita comprensión del ser, Heidegger afirma, y adhiero con su planteo, que entre ser y ente radica una diferencia ontológica radical:

El Ser es aquello que determina al ente como ente, aquello respecto de lo cual el ente, sea como fuere en cada caso se lo refiere, siempre es ya en cada caso comprendido. El ser del ente no "es" el mismo un ente (Heidegger, 1997, 6).

La diferencia ontológica sostenida por Heidegger, y ya planteada anteriormente por Tomás, es una diferencia real: el ente es "aquello que es" (illud quod est) y el ser es "aquello por lo cual el ente es" (illud quo ens est). De 


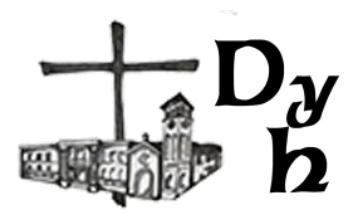

esta forma, la doctrina tomista escapa al reproche heideggeriano del porque el esse tomista es el acto de la esencia, siendo ambos principios constitutivos y fundantes del ente. Por otro lado, y ya que Tomas plantea que Dios no es ente sino el ser mismo que trasciende todo, su planteos esquiva la denuncia que realiza Heidegger a la metafísica occidental por su carácter eminentemente onto-teo-lógico.

Considerando esto, estamos en condiciones de afirmar que el pensamiento de ambos autores se vincula directamente en este punto ya que exponen la primacía del ser sobre el ente. Por un lado, el acto de ser tomista, al actualizar la esencia, hace que el ente sea. Por el otro, "el sein heideggeriano trae el Seiende a la presencia del Dasein, sacándolo del estado de oculto o de latencia en el que se encontraba" (Marenghi, 2019, 142).

En este sentido, debemos admitir que es el filósofo de Friburgo el responsable de, en la filosofía contemporánea, realizar esfuerzos para restaurar la incógnita primordial de la metafísica que alude a la cuestión del ser: "Si el ente se dice en múltiples significaciones, ¿cuál es, entonces, la significación fundamental de todas ellas? ¿Qué significa ser?" (Heidegger, 1968, 34).

De todas formas, Heidegger no se contenta solamente con denunciar. Como comenté anteriormente, el filósofo de Friburgo se propone ocuparse de lo que la metafísica ha ignorado de forma tal que esclarece la situación planteando tres niveles epistemológicos: las ciencias particulares, lógicamatemáticas, físicas y humanas; las ontologías regionales, encargadas de los entes ideales, naturales y culturales; y la ontología fundamental que, como es de esperar, se encarga del mismo ser.

Ahora bien, ¿Cómo complementar el planteo tomista con el que hace Heidegger en la modernidad? Particularmente, creo que es importante no caer en pensamientos autodeterministas en los cuales el hombre construye su esencia, como lo hace Sartre en sus famosos planteos respecto al ser en sí y el ser para sí. Por ello, de la misma forma que Sartre y el existencialismo ateo considera al hombre como un ser-para-sí, considero que Heidegger yerra en plantear al hombre como algo indeterminado que debe determinarse por sí mismo. Sin embargo, creo que sería muy interesante complementar la filosofía tomista con el concepto de Existenz de Heidegger que plantea a la persona como una cosa abierta totalmente al mundo, es decir, no en tanto determinar 
su esencia sino más bien, teniendo una esencia determinada, la completa y perfecciona en el mundo. En la misma línea, sería sumamente interesante retomar el concepto de apertura que pesquisa Wojtyla en su filosofía personalista. En fin, será tarea para otra oportunidad, aunque, más allá de la respuesta específica a la incógnita planteada, puedo afirmar que el verdadero trabajo intelectual crítico conduce a la verdad, aquella que tanto deseamos los humanos, que nos hace libres y nos conduce a la realización personal.

La cuestión aquí es clara. Tomás y Heidegger, a pesar de sus diferencias, coinciden en un punto crucial: el ser no es el ente. Ambos pertenecen a dos esferas completamente distintas que debemos diferenciar para que no caer en vagas confusiones. El "es" no es algo del ente que se pueda observar, sino que pertenece a lo ontológico, mientras que el ente refiere a la esfera óntica.

\section{Conclusión}

Todo hombre quiere conocer, así lo expresa Aristóteles al comienzo de su tan famosa Metafísica. Pensar esta afirmación, luego de varios siglos de que fue escrita, no me deja otra opción que reafirmarla con énfasis. El mismo Agustín será quien, a pesar de que muchos lo contrapongan al Estagirita, amplié esta idea dando cuenta de que el corazón del hombre está inquieto hasta que no descansa en Algo Mayor que lo realicé plenamente. Incluso, un autor tan característico de los ideales modernos como Freud adherirá a la expresión aristotélica, quizás implícitamente, al plantear, en su famosa Interpretación de los Sueños, que el aparato psíquico se mueve a deseo, un deseo que quiere reencontrarse con algo primario y que nunca llega a su plenitud en la vida. Quizás éste sea el espíritu de búsqueda verdadero que inspiró al mismo Juan Pablo II a escribir su famosa Fides Et Ratio. En definitiva, se nos presenta una verdad indiscutible y, cómo decía Descartes, evidente: el hombre desea la verdad y, sin ella, no es libre. Qué sabiduría la de aquel antiguo filósofo griego, llamado Sócrates, que intuyó esta idea y pregonaba por las calles atenienses exhortando a sus co-ciudadanos a conocerse a sí mismo. Escribo estas palabras porque creo que aquí se pone en juego la dimensión humana en absoluto. En este contexto atravesado por, en términos de Jasper, la situación límite de la 


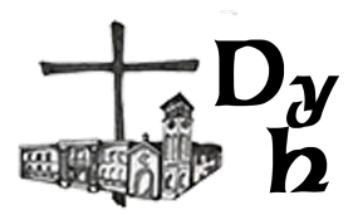

pandemia mundial, me he dado cuenta que en la metafísica se definen cuestiones profundas con una gran relevancia teórica, pero, aún más, práctica ya que, de alcanzar la difusión, todo pensamiento filosófico deviene en praxis.

Éste es el desafío que hoy se nos presenta. Quizás, en términos de grieta, el campo filosófico se tiñe de dos bandos claros. Uno abogado por el realismo, retomando aquella filosofía antigua y medieval en donde empezó todo. El otro, en un olvido y hasta desprecio hacia aquellos primeros filósofos, enarbola los ideales de la modernidad cayendo en relativismos, idealismos y positivismos. Es hora, si se quiere, de tomar la pluma y tratar de sintetizar, con el peso hegeliano de la palabra, estas posturas dicotómicas. Heidegger, como plantea el escrito, acusa a toda la metafísica precedente por un "olvido del ser" atroz, que dejo sin objeto formal y propio a la disciplina. Incluso, llega a identificar al ser con la nada ya que, utilizando un juego de palabras, nada se puede decir de ambos. Yendo en contra, cómo queda en evidencia, del principio de no contradicción, base fundamental para toda filosofía seria. Ésta imposibilidad de "decir algo" respecto al ser, es la que nos conduce a posiciones que niegan radicalmente la metafísica. Entre ellas, podemos pensar al positivismo, del que increíblemente aún quedan resabios, y el idealismo trascendental kantiano, que incluso en su distinción entre fenómeno y noúmeno niega también la capacidad humana de conocer a la cosa en sí.

Ahora bien, creo que desde un marco realista tenemos la oportunidad enorme de retomar al mismo Tomas quien, a pesar de que la modernidad lo niegue, es el autor realmente original respecto a la cuestión aquí discutida. Lo primero que debemos retomar es que la filosofía tomista, a pesar de retomar la ontología esencialista de Aristóteles, la supera al distinguir entre esencia y ser, entendiendo a este último como acto de la primera, un planteo que, como hemos visto, es harto original.

Mucho antes que Heidegger se preguntase acerca del Ser cómo aquello que ha estado olvidado a pesar de fundamentar la filosofía, Tomas de Aquino supera el esencialismo aristotelismo y diferencia la esencia del ser, para poner el foco en este último como el gran principio constitutivo.

Considerando esto, podemos mencionar que ser y esencia son coprincipios indisociablemente articulados en todo ente: el ser es siempre de un ente determinado por cierto modo específico. No debemos perder de vista que 
ser y esencia son aquello por lo cual un ente es lo que es, sin ser ellos mismos entes. Olvidar esto y tomarlos como si fueran cosas constituye un grave error que puede conducirnos a insalvables aporías metafísicas. Otro error, el cual hay que evitar, refiere a derivar uno de estos componentes del otro, pensando así que la esencia precede la existencia o en donde la existencia precede a la esencia. Para no caer en estos extremos, debemos reconocer que en el conocimiento de todas las cosas desde sus principios, de ahí el nombre de Filosofía Primera, chocamos con esta dualidad irreductible: el ente es siempre un todo estructurado de ser y esencia, en donde la primacía del ser no debe suprimir el valor de la esencia.

\section{Bibliografía}

Aristóteles (2018). Metafísica. Barcelona: Gredos.

Fabro, C. (2009). Participación y causalidad. Navarra: Eunsa.

Gilson, E. (1951). El ser y la esencia. Buenos Aires: Desclée.

Heidegger. M. (1997). Ser y tiempo. Chile: Editorial Universitaria.

Lanusse, J. (2020). El debate en torno a la mímesis en la República de Platón y en la Poética de Aristóteles. Dios Y El Hombre, 4(1), 055.

Marenghi, C. (2018). La originalidad de la ontología tomista y su giro en torno al ser. Studia Gilsoniana 7, no. 1 (January-March 2018): 33-67.

Marenghi, C. (2019). El oscurecimiento del ser y su sustitución por la existencia. Studia Gilsoniana 8, no. 1 (January-March 2019): 113-149.

Tomás de Aquino (2006). Suma Teológica. Madrid: Biblioteca de autores cristianos. 